\title{
We share the euro, but not our humanity: Humanity attributions are associated with the perceived causes, consequences, and solution to the Greek financial crisis
}

\author{
Mario Sainz $^{\mathrm{a}, *}$, Steve Loughnan ${ }^{\mathrm{b}}$, Friederike Eyssel ${ }^{\mathrm{c}}$, Afroditi Pina ${ }^{\mathrm{d}}$ \\ a Mind, Brain, and Behaviour Research Centre (Centro de Investigación Mente, Cerebro y Comportamiento; CIMCyC), Faculty of \\ Psychology, University of Granada, Campus Universitario de Cartuja, 18011 Granada, Spain \\ b School of Philosophy, Psychology and Language Sciences, University of Edinburgh, Edinburgh, EH8 9JZ, United Kingdom \\ c Department of Psychology, Center of Excellence Cognitive Interaction Technology, University of Bielefeld, Bielefeld, 33619, Germany \\ d School of Psychology, University of Kent, Canterbury, CT2 7NP, United Kingdom
}

\section{A R T I C L E I N F O}

\section{Article history:}

Received 12 November 2018

Received in revised form 15 March 2019

Accepted 15 March 2019

Available online $\mathrm{xxx}$

\section{Keywords:}

Dehumanization

Economic conflict

Intergroup relations

European Union

\begin{abstract}
A B S T R A C T
Political and financial crises are complex and multi-determined situations whose solutions depend on multiple factors. To understand these conflicts, we explore to what extent mutual outgroup dehumanization along with ingroup humanization between the parts involved in the conflict predict the interpretation of the different facets of the political situation (i.e. interpretation of the crisis, the perceived consequences, or the possible solutions). In this article, we focused on the dispute between Germany and Greece catalyzed by a Greek referendum in 2015. We assessed to what extent mutual (de)humanization between Germans and Greeks predicted the interpretation of the conflict. Our results showed a mutual dehumanization: Greeks mechanizing Germans and Germans animalizing Greeks. For Germans, dehumanizing the Greeks was linked to worse perceived Greek financial administration and minimizing the perception of the Greeks' suffering, whereas humanizing the ingroup was associated with more outgroup responsibility. For Greeks, dehumanizing the Germans was associated with a desire to avoid German financial control, whereas ingroup humanization was associated with better financial administration, less responsibility, and a higher perception of suffering among Greeks. In short, dehumanizing the other members of the European Union (EU) while humanizing their own nationality contributed to the neglect of the problems inside the EU, shaping the understanding of the economic conflict among both nations.
\end{abstract}

(c) 2019 Western Social Science Association. Published by Elsevier Inc. All rights reserved.

\section{Introduction}

Many countries are facing complex, multi-determined crises. In this study, we focused on whether outgroup dehumanization and ingroup humanization act as components

\footnotetext{
* Corresponding author.

E-mail addresses: msainzmartinez@ugr.es
} (M. Sainz), steve.loughnan@ed.ac.uk (S. Loughnan), friederike.eyssel@uni-bielefeld.de (F. Eyssel), a.pina@kent.ac.uk (A. Pina). of these conflicts, shaping interpretations and willingness to find common solutions.

We focused on the financial recession that the European Union (EU) has faced since 2008. To address these financial difficulties, the EU has advocated for economic reforms in the Eurozone, which are not unilaterally endorsed by all Euro nations. These differences between Euro nations regarding the financial policies that should be implemented and the current disparities between the national economies have resulted in a cycle of blame between countries, often portrayed in the media and popular discourse 
as a conflict. This was exemplified, for instance, when the German Chancellor Angela Merkel was portrayed as an unemotional, robotic "terminator" (New Statesman, 2012) and when the Greek citizens were portrayed as lazy and greedy (BILD Zeitung, 2015). With this context in mind, we examined how Greeks and Germans perceive the causes, consequences, and possible solutions to the Eurozone conflict. Specifically, we posited that (de)humanization feeds the conflict from the perspective of the main nations involved and influences the perception of injustice and wrongdoing and thus the perception of potential consequences and possible solutions.

\subsection{Humanness and dehumanization}

Viewing the ingroup as more human than an outgroup is a common intergroup process (for reviews, see Haslam \& Loughnan, 2014; Vaes, Leyens, Paladino, \& Miranda, 2012). Dehumanization is understood as the process of differentially attributing and denying humanity to others (Haslam, 2006), typically finding that people consider their ingroup to be more human than the outgroup. Based on Haslam's (2006) dual model of dehumanization, two dimensions have been proposed. The first is human uniqueness (HU), which reflects aspects of humanity that distinguish humans from animals, such as civility, rationality, and refinement. The denial of these characteristics leads to viewing the group as closer to animals than to human beings (i.e., animalistic dehumanization). This form of dehumanization has usually been applied to lowstatus (Capozza, Andrighetto, Di Bernardo, \& Falvo, 2011; Iatridis, 2013) or poor groups (Loughnan, Haslam, Sutton, \& Spencer, 2014; Sainz, Martínez, Moya, \& Rodríguez-Bailón, 2018). Additionally, animalizing disadvantaged groups might trigger a justification of inequality by considering that these groups are placed where they deserve (Haslam \& Loughnan, 2014).

The second dimension proposed in Haslam's (2006) dual model of dehumanization focuses on what is considered "core" or "essential" to being human. The human nature (HN) dimension encompasses traits such as emotionality, cognitive openness, or depth. The denial of HN characteristics leads to a mechanistic dehumanization, where others are considered cold and unemotional, like robots or machines. This form of dehumanization exists in many areas, such as medicine (Vaes \& Muratore, 2013) and the workplace (Andrighetto, Baldissarri, \& Volpato, 2017). More recently, Sainz et al. (2018) also demonstrated that wealthy groups can be mechanized. This perception of advantaged groups as unemotional machines without any concern for others could influence what people expect from these groups or how people interact with them.

Although previous work has focused mainly on denial of humanity or on the differential attribution of particular forms of dehumanization to different social groups (Haslam \& Loughnan, 2014), further studies have also shown that people attribute $\mathrm{HN}$ and $\mathrm{HU}$ in a complementary fashion. That is, people sometimes attribute one form of humanity to the ingroup and another form to the outgroup. For example, Bain, Park, Kwok, and Haslam (2009) examined how Australians and Chinese people viewed each other in terms of humanness. They found that both agreed that Australians had higher levels of $\mathrm{HN}$ and that Chinese people had higher levels of HU. These findings reflect a consensual attribution of $\mathrm{HN}$ and $\mathrm{HU}$, whereby both groups emphasize the humanness dimension that is more salient, and probably more important to their respective cultures (Paladino \& Vaes, 2009), for the ingroup. At the same time, the other dimension is attributed to a higher degree to the outgroup, thus showing that the ingroup is not necessarily considered superior in both dimensions of humanity. In another set of studies, Leidner, Castano, and Ginges (2013) discovered a similar finding in the context of the conflict between Israelis and Palestinians. These authors showed that complementary dehumanization between Israelis and Palestinians fueled the conflict and led to support for a direct punishment of the outgroup. Based on both studies, we can conclude that the attribution and denial of humanity to the ingroup and the outgroup are two processes that can influence intergroup relations.

However, as Vaes et al. (2012) pointed out, the roles of ingroup and outgroup humanity should be discussed separately. This is because they could be influenced by separate variables and could also be associated with different consequences for intergroup relations. On one hand, it can be expected that a higher attribution of humanity to the ingroup will lead to a glorification of one's group, which might also minimize perceived ingroup responsibility (Koval, Laham, Haslam, Bastian, \& Whelan, 2011; Leidner, Castano, Zaiser, \& Giner-Sorolla, 2010). On the other hand, outgroup dehumanization might shape the interpretation of a conflict by placing responsibility on the dehumanized others (Bastian, Laham, Wilson, Haslam, \& Koval, 2011). To date, the influence of both processes has not yet been examined jointly to explain economic conflicts, such as the one triggered by the economic recession in the EU. Therefore, in this paper, we will examine the role of ingroup and outgroup dehumanization in the context of an economic conflict.

\subsection{Mutual (De)humanization and economic conflicts}

Although previous authors have suggested that dehumanization might trigger economic conflicts (Kraus, Park, \& Tan, 2017), dehumanization has been predominantly studied in the context of intergroup violence (e.g., Bandura, 1999). This neglect is important because dehumanization has been shown to justify intra-national economic differences (e.g., Sainz et al., 2018). In the present study, we examined this effect between nations, exploring whether dehumanization between Greeks and Germans plays a role in their economic conflict. Specifically, given that animalistic and mechanistic dehumanization lead to different outcomes (see Vaes et al., 2012), it is unlikely that both forms of dehumanization will impact economic conflict in the same way. When a group is animalized, they should be viewed as not only inferior but as less rational and capable of controlling their own economy. Therefore, animalized groups could be considered responsible for their situation, blamed, and in need of external control to solve their economic problems. By contrast, when a group is mechanized, they are viewed as lacking emotion and empathy, two fac- 
tors that might weaken relational ties and a sense of shared experience in the economic conflict. This emotional distance might cause people to feel that the mechanized group does not care about the ingroup's needs and decrease the desire for a shared solution. In short, we proposed that animalistic and mechanistic dehumanization might shape the interpretation of the conflict, in a different manner, but with a common consequence: the maintenance of the economic conflict and the economic disparities among groups.

The current work also helps us understand the timeline of conflict and dehumanization. Previous researchers have examined a range of conflicts at various points in the cycle (Bar-Tal, 1989). For example, Castano and GinerSorolla (2006) found that White Americans dehumanized Native Americans more when reminded of White atrocities during colonization. In the European context, Čehajić, Brown, and Gonzalez (2009) found that Serbians dehumanized Bosnians when reminded of the Bosnian genocide. Moreover, other studies have focused on conflicts such as the Israeli-Palestinian dispute and how mutual dehumanization can play a role in a longstanding conflict (Leidner et al., 2013). However, to our knowledge, no research has yet examined the role of dehumanization during the peak of the conflict.

\section{The present research}

In the present research, our aim was to focus on whether ingroup and outgroup (de)humanization among Germans and Greeks was linked to the public perception of the causes, consequences, and solutions to the economic conflict inside the EU. Thus, we conducted two exploratory online studies in Germany and Greece during the referendum conflict (Greek referendum to negotiate the conditions of the bailout) in order to examine the relation between the variables we were interested in. We hypothesized processes of mutual dehumanization between Germans and Greeks:

First, regarding outgroup (de)humanization: we expected that Greece-one of the EU's less economically stable countries, popularly described in the press with the derogatory acronym PIIGS (Portugal, Italy, Ireland, Spain, Greece; BBC News, 2010)-would be viewed by the Germans as lacking HU. Specifically, in line with previous studies about poor groups (Loughnan et al., 2014; Sainz et al., 2018), we expected that the Greeks would be considered by Germans to be lacking HU compared to HN (Hypothesis 1). We further expected that Germans would be viewed by the Greeks as lacking HN while having high levels of $\mathrm{HU}$ instead (H2), in line with Martínez, Rodríguez-Bailón, and Moya (2012).

Second, regarding ingroup humanity: we expected that the Germans would consider themselves as having more HU than HN (H3), whereas the Greeks would see themselves as having higher HN than HU (H4). This pattern of results would highlight that groups tend to ascribe to themselves the dimension of humanity that is denied to the other target involved in the conflict (i.e., complementary attribution of humanity; Bain et al., 2009). Furthermore, we hypothesized that ingroup and outgroup (de)humanization would shape the interpretation of the economic situation:

\subsection{German study hypotheses}

\subsubsection{Ingroup humanity hypotheses}

We expected that for the Germans, ingroup HU would predict a lack of ability to manage the economic recession on the part of the Greeks (i.e., worse administration, more responsibility for the economic bailout and higher desire to control the Greek economy [H5]). On the other hand, ingroup HN would minimize the Germans' concern about the Greeks (i.e., minimization of the consequences and lower debt relief [H6]).

\subsubsection{Outgroup humanity hypotheses}

We expected that for Germans, the lack of HU in the outgroup (i.e., their perception that the Greeks are animal-like) would predict that the Greeks are blamed for their economic bailout (i.e., poorer ability to deal with their finances, more Greek responsibility for the crisis and a greater desire to control the Greek economy [H7]).We also expected that outgroup HN would be related to the Greeks' perceived capability to suffer (i.e., minimization of the consequences and lower debt relief [H8]).

\subsection{Greek study hypotheses}

\subsubsection{Ingroup humanity hypotheses}

We expected that ingroup HU would predict that the Greeks would be perceived as capable of managing their economy (i.e., proper administration and less responsibility for their financial crisis [H9]). Additionally, ingroup HN would predict consequences of the crisis and the desire to receive autonomous aid from the EU (i.e., higher recognition of the level of suffering, debt relief, and the desire to avoid control over their economy [H10]).

\subsubsection{Outgroup humanity hypotheses}

For Greeks, we expected that the ascription of HU to the Germans would lower the perceived capability of economic administration of the Greeks (i.e., lower the perceived capability and more ingroup responsibility for the economic recession in the case of the Greeks [H11]). Moreover, the lack of HN (or the Greeks mechanizing the Germans) would result in the perception that Germans do not care about the well-being of Greeks (i.e., minimization of consequences, lower debt relief, and lower desire for German control [H12]).

Finally, due to the reason that we wanted to isolate the effect of group (de)humanization from the general positive or negative attitudes about the in-/out-group, we controlled by attitudes on the analysis. Our hypothesis is that the above mentioned pattern of results (i.e., HU or $\mathrm{HN}$ predicting the interpretation of the conflict) would be presented even when controlling by outgroup derogation (i.e., negative attitudes) and ingroup glorification (i.e., positive attitudes) on the analysis. Data can be found online (osf.io/97v3s). 


\section{Method}

\subsection{Participants}

We conducted two online studies, one in Germany ( $n=83,41$ women, 42 men, $M_{\text {age }}=32.19, S D=11.64$ ) and the other in Greece ( $n=69,48$ women, 21 men, $M_{\text {age }}=35.53$, $S D=8.42$ ). Participants from both nations, drawn from the general population and recruited online via social media, volunteered to complete an online questionnaire in the days following the Greek referendum (July 5th, 2015). The studies were active for one week (July 16th-23rd, 2015) when the conflict was at its peak because Greek voters had rejected the European-brokered bailout. Power analysis (Faul, Erdfelder, Buchner, \& Lang, 2009) indicated that for a multiple regression analysis (three predictors, medium effect size $f^{2}=.15, \alpha=.05,80 \%$ Power, required sample $=77$ ), the study would have benefitted from a bigger sample size. However, data collection was deliberately scheduled specifically for the days after the referendum so that we could analyze the influence of dehumanization during the peak of the economic conflict. As a result, the size of the data sample was constricted by the limited time available for data collection.

\subsection{Materials and procedure}

Participants volunteered to take part in a study about the economic situation in Greece. The content of both surveys was the same. The survey was originally created in English and translated into German and Greek by native speakers. We obtained ethics approval for this project from the lead author's institution. Responses were made on a 7-point Likert scale, with high scores reflecting strong endorsement of the statements or a high attribution of traits to the target. The order of the questions relating to the Germans and the Greeks was counterbalanced. Participants required around $10-15 \mathrm{~min}$ to complete the questionnaire.

\subsubsection{Mutual dehumanization}

Participants in both studies rated the ingroup and the outgroup's humanity using an 8-item scale (Bastian, Jetten, \& Radke, 2012). Participants rated the level of HN (e.g., "Germans/Greeks are mechanical and cold, like robots" [reversed]; Cronbach's $\alpha$ ranged from .55 to .72) and the level of HU (e.g., "Germans/Greeks are rational and logical"; two items were excluded due to low reliability, final $\alpha$ ranged from .71 to .75).

\subsubsection{Perceived causes of the crisis}

To assess the perceived origins of the Greek crisis, we included similar items to the ones used when measuring group responsibility (Čehajić et al., 2009). Participants completed three items related to the financial administration of the Greek economy (e.g., "Greeks have been wasting the money that the EU gave to them" [reversed]; $\alpha=.64$ ) and three items regarding the responsibility of Greeks (e.g., "the Greeks are mostly responsible for the current economic crisis"; $\alpha=.71$ ).

\subsubsection{Consequences of the crisis}

To assess people's beliefs about the harm being caused by the crisis, we created some items based on previous items to measure the perceived suffering in other contexts (Loughnan, Pina, Vasquez, \& Puvia, 2013). In our study, both the Germans and the Greeks reported the extent to which the crisis was causing hardship and suffering in Greece with six statements (e.g., "To what extent are the Greeks suffering because of the current economic crisis?", "Are Greeks complaining too much about the austerity measures?" [reversed]; $\alpha=.77$ ).

\subsubsection{Attitudes toward crisis solutions}

The potential debt relief solution to the crisis was measured by having the Germans and the Greeks report the amount of Greek debt that should be paid by the EU using a slider (from 0 to $100 \%$ of the debt). This question was based on similar items measuring support for helping disadvantaged groups (e.g., Henry, Reyna, \& Weiner, 2004). In addition, participants were asked about the specific conditions of debt relief. Participants responded to three questions, inspired by the literature about helping behaviors as a tool to maintain the status quo (Nadler, 2002), about possible financial control/freedom of the Greek economy (e.g., "The Greeks need the Germans to direct their financial policy," "Greeks are able to solve the economic problems by making their own decisions" [reversed]; $\alpha=.69$ ).

\subsubsection{Other measures}

Basic demographics including age and gender were gathered at the beginning of the questionnaire. To measure attitudes toward the ingroup and the outgroup, participants answered using an attitude thermometer about Germans and Greeks. Ratings ranged from 0 (extremely unfavorable) to 100 (extremely favorable).

\section{Results}

Firstly, we calculated simple statistics (see online information). Secondly, we examined mutual attribution of humanity before turning to the association between in/outgroup (de)humanization and the interpretation of the economic recession.

\subsection{Mutual dehumanization}

We calculated a repeated-measures ANOVA with Humanity (HU vs. HN) and Group (ingroup vs. outgroup) as within-subject factors, and Nationality (German vs. Greek) as a between-subjects factor. Results showed a main effect of Humanity, $F_{(1,150)}=60.01, p \leq .01, \eta^{2} p=.29$, and Group, $F_{(1,150)}=4.65, p=0.03, \eta^{2} p=.03$. Importantly, there were significant interactions between Humanity and Nationality $F_{(1,150)}=47.88, p<.001, \eta^{2} p=.24$, and between Group and Nationality $F_{(1,150)}=11.07, p<.001, \eta^{2} p=.07$. Furthermore, these results were qualified by a significant three-way interaction between Humanity, Group, and Nationality, $F_{(1,150)}=16.83, p \leq .001, \eta^{2} p=.10$. Regarding the outgroup evaluation, simple effects revealed that the Germans attributed a lower level of HU to the Greeks 
Table 1

Means and $S D$ of ingroup and outgroup humanity, both Human Uniqueness (i.e., HU) and Human Nature (i.e., HN), as a function of group membership (German and Greek study).

\begin{tabular}{|c|c|c|c|c|}
\hline & \multicolumn{2}{|c|}{ German study } & \multicolumn{2}{|c|}{ Greek study } \\
\hline & Outgroup & Ingroup & Outgroup & Ingroup \\
\hline $\mathrm{HU}$ & $4.08(.92)^{\mathrm{a} 1}$ & $4.61(.94)^{\mathrm{a} 2}$ & $4.09(1.06)^{a}$ & $4.42(1.07)^{\mathrm{a} 1}$ \\
\hline $\mathrm{HN}$ & $5.02(.77)^{\mathrm{b} 1}$ & $4.33(.78)^{\mathrm{b} 2}$ & $2.96(1.17)^{\mathrm{b} 1}$ & $5.41(.70)^{\mathrm{b} 2}$ \\
\hline
\end{tabular}

Note. Values with different superscripts across columns (i.e., letters) and files (i.e., numbers) are significantly different from each other, $p<.05$.

$(M=4.08, S D=.92)$ than to themselves $(M=4.61, S D=.94$, $t_{(82)}=4.19, p \leq .001,95 \%$ CI $[-.78,-.28]$, Hedges' $\left.g=0.56\right)$, whereas Greeks attributed a lower level of HN to the Germans $(M=2.96, S D=1.17)$ than to themselves $(M=5.41$, $S D=.70, t_{(68)}=13.27, p \leq .001,95 \%$ CI [2.08, 2.82], Hedges' $g=2.54)$. Therefore, these results reflect mutual dehumanization, with the Germans viewing the Greeks as relatively lacking in $\mathrm{HU}$ (i.e., animal-like) and Greeks considering the Germans to be lacking in HN (i.e., machine-like), supporting $\mathrm{H} 1$ and $\mathrm{H} 2$ (Table 1).

Regarding the ingroup evaluation, simple effects revealed that the Germans considered themselves as having more $\mathrm{HU}(M=4.61, S D=.94)$ than $\mathrm{HN}(M=4.33, S D=.78$, $t_{(82)}=2.35, p=.02,95 \%$ CI $[.04, .51]$, Hedges' $\left.g_{a v}=.32\right)$, whereas Greeks perceived themselves as having more $\mathrm{HN}$ $(M=5.41, S D=.70)$ than $\mathrm{HU}\left(M=4.42, S D=1.07, t_{(68)}=8.84\right.$, $p \leq .001,95 \% \mathrm{CI}[.77,1.22]$, Hedges' $g=1.09)$. Additionally, attributions of humanity revealed that the Germans perceived the Greeks as having more $\mathrm{HN}(M=5.02, S D=.77)$ than $\mathrm{HU}\left(M=4.08, S D=.92, t_{(82)}=10.81, p \leq .001,95 \% \mathrm{CI}\right.$ $[.77,1.11]$, Hedges' $g=1.10)$, whereas the Greeks perceived the Germans as having more $\mathrm{HU}(M=4.09, S D=1.06)$ than HN $\left(M=2.96, S D=.1 .17, t_{(68)}=7.80, p \leq .001,95 \%\right.$ CI $[.84$, $1.42]$, Hedges' $g=1.01)$. In short, these results support $\mathrm{H} 3$ and $\mathrm{H} 4$ regarding the complementary attribution of humanity.

\subsection{Dehumanization and interpretation of the conflict}

To analyze the roles of outgroup dehumanization, ingroup humanization, and attitudes between countries, we ran simultaneous multiple regression analyses using humanity attributions ( $\mathrm{HU} / \mathrm{HN})$ and attitudes as predictors of the causes, consequences, and solutions of the economic crisis for both the Germans and the Greeks. Due to the amount of analysis we conducted, we applied a more conservative critical $p$ value of .025 on the analysis (Bonferroni correction). To provide a clear exposition of our results, we split the results to show the interpretation of the conflict from the point of view of the Germans and the Greeks, sequentially.

\subsubsection{Germans' interpretation of the conflict}

We ran multiple regression analysis using humanity attributions (HU/HN) for the ingroup (i.e., Germans) and for the outgroup (i.e., Greeks) and using ingroup/outgroup attitudes as predictors of the causes, consequences, and solutions of the economic crisis for the German sample (Table 2). The results are summarized in the following:
4.2.1.1. Dehumanization and perceived causes of the crisis. Regarding the perceived causes of the crisis, the results for the German sample showed that ingroup attitudes predicted both administration errors $(\beta=-.02, S E=.01, p=.01)$ and Greek responsibility for the crisis $(\beta=.02, S E=.01$, $p=.02$ ). In addition, the attribution of HU to the ingroup predicted higher Greek responsibility during the crisis $(\beta=.52, S E=.17, p \leq .001)$. We conducted the same analysis using humanity and attitudes about the outgroup (i.e., Greeks). The results indicated that for the Germans, the level of Greek $\mathrm{HU}(\beta=.42, S E=.18, p=.02)$ and negative attitudes about the outgroup $(\beta=.03, S E=.01, p \leq .001)$ were associated with negative appraisals of the Greeks' financial administration. It seems that the Germans viewed the ingroup as especially positive and rational but also perceived the Greeks as animals. This was associated with a higher tendency to blame the Greeks for their situation.

Specifically, the results indicated that German humanity did not predict Greek administration, whereas the results highlighted that humanization of the Germans by means of HU attribution predicted Greeks' (outgroup) responsibility for the crisis. Also, Greeks' HU predicted a worse administration of the Greek economy above outgroup negative attitudes. Additionally, Greek humanity did not predict Greeks' responsibility for the economic recession. Moreover, a positive perception of the ingroup led to the conclusion that the Greeks' administration of their economy was inferior to that of the Germans. Finally, outgroup responsibility was not predicted by outgroup humanity. Uniquely, a negative perception of the Greeks marginally predicted the view that the Greeks had a higher level of responsibility for the crisis.

4.2.1.2. Dehumanization and consequences of the austerity policies. Regarding the perception of the consequences of the economic recession, the results for the Germans indicated that for the Germans, ingroup attitudes negatively predicted perceived suffering of the Greeks $(\beta=-.02$, $S E=.00, p \leq .001)$. The more positive attitudes about the ingroup, the more Germans reported that Greeks complained too much about the crisis. Also, the animalization of Greeks was associated with the notion that Greeks complain too much about the crisis $(\beta=.34, S E=.14, p=.01)$. It seems that Germans minimize the suffering among the Greek population by maintaining a positive perception of themselves while considering Greeks to be animal-like.

4.2.1.3. Dehumanization and solutions. Results regarding the possible solutions indicated that in the German sample, debt relief was mainly predicted by attitudes toward the ingroup $(\beta=-.39, S E=.15, p=.01)$, even when a marginal 


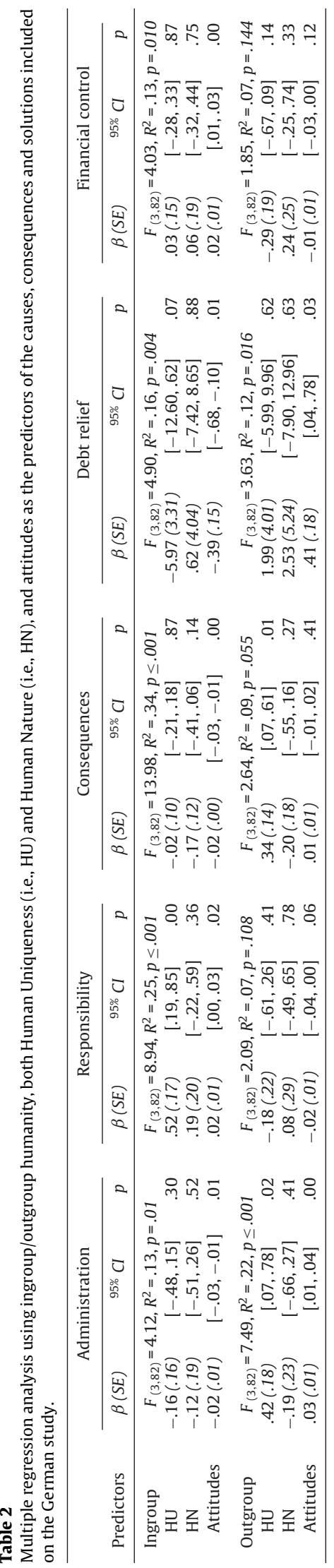

effect (critical $p$ value of .025) also appears regarding the outgroup $(\beta=41, S E=.18, p=.03)$. Moreover, more positive ingroup attitudes were linked to a perceived desire to control Greek finances $(\beta=.02, S E=.01, p \leq .001)$. In short, positive ingroup attitudes seem to have driven the solution that German participants were willing to endorse.

Therefore, on the German sample results are mainly driven by ingroup or outgroup attitudes. Humanity attributions, both ingroup (H5 and 6) and outgroup humanity (H7 and 8) did not seem to play a main role in the present study.

\subsubsection{Greek interpretation of the conflict}

We conducted multiple regression analysis using humanity attributions (HU/HN) for the ingroup (i.e., Greeks) and the outgroup (i.e., Germans) and ingroup/outgroup attitudes as predictors of the causes, consequences, and solutions of the economic crisis for the German sample (Table 3). The results are summarized in the following:

4.2.2.1. Dehumanization and perceived causes of the crisis. Regarding the perceived causes of the crisis, the results for the Greek sample showed that the attribution of HN to the ingroup predicted a competent financial administration of the Greek economy $(\beta=57, S E=.24, p=.02)$ and lower levels of Greeks' responsibility for their economic situation ( $\beta=-.70, S E=.24, p \leq .001)$. In short, ingroup humanity for the Greeks seemed to lower the responsibility placed on the Greek population for the economic recession. However, the Greeks highlighted that it was their HN and not their ascribed level of HU, as was previously predicted (H9), the dimension that lowered Greeks' (ingroup) responsibility for the crisis. Regarding the humanity and attitudes about the outgroup, the results indicated that Greeks considering Germans to be machine-like (i.e., low $\mathrm{HN}$ ) was the predictor of judgements of error in the Greek financial administration $(\beta=-.48, S E=.15, p \leq .001)$, instead of HU. However, the attribution of HU to the Germans predicted Greek responsibility during the economic recession $(\beta=.40, S E=.15, p=.01)$, in line with H11. Therefore, it seems that viewing the Germans as lacking HN was associated with a tendency to believe that Greeks had not been wasting EU money. At the same time, perceiving Germans as rational and civilized was associated with a tendency to attribute more responsibility for the current situation to the Greeks (ingroup).

4.2.2.2. Dehumanization and consequences of the austerity policies. Results regarding the consequences of the economic crisis showed that Greek ingroup attribution of HU (not HN) was marginally (critical $p$ value of .025 ) linked to the belief that the ingroup suffers greatly $(\beta=.25, S E=.11$, $p=.03$ ); the more the Greeks humanized the ingroup by distancing themselves from animals, the more they reported suffering as a consequence of the austerity policies. On the contrary, dehumanizing the Germans on both dimensions and disliking them were not significant predictors of the Greeks' suffering caused by the consequences of the economic crisis in a simultaneous multiple regression analysis. However, when we ran the regression analysis only with 


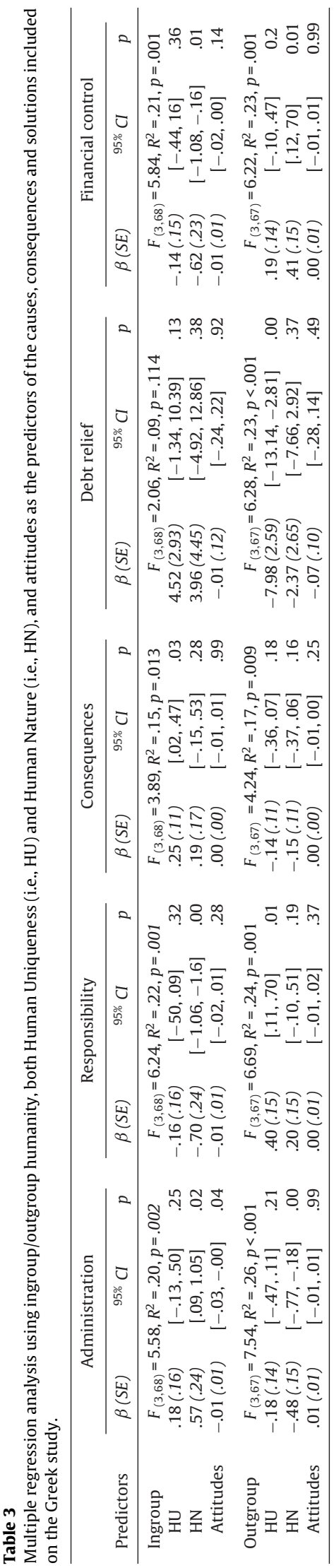

German HU and HN as the predictors of the negative consequences of the austerity policies for the Greeks, the results showed that the denial of HN to the Germans negatively predicted the Greeks' suffering during the economic recession $\left(F_{(1,68)}=9.44, \beta=-.271, S E=.088, p=.003, R^{2}=.124\right)$. In line with $\mathrm{H} 12$, the more Germans were considered to be unemotional machines, the more the Greek participants thought that Germans did not care about the suffering of the Greek population.

4.2.2.3. Dehumanization and solutions. Results regarding the Greek sample showed that debt relief was not predicted by ingroup humanity or attitudes, while ingroup HN negatively predicted the German control over the Greek economy $(\beta=-.62, S E=.23, p=.01)$. The more the Greeks considered themselves to be human in terms of their warmth or cognitive flexibility, the more they rejected German control, in line with H10. Regarding outgroup humanity and attitudes, the results indicated that the attribution of $\mathrm{HU}$ (not the attribution of $\mathrm{HN}$ ) to the Germans negatively predicted the support for debt forgiveness ( $\beta=-7.98, S E=2.58, p \leq .001)$. Also, considering the Germans to be machine-like predicted the Greeks' desire to avoid German financial control over the Greek economy $(\beta=.41, S E=.15, p=.01)$, in line with H12. In short, Greek HN predicted Greeks' desire to make their own decisions, and German HN predicted Greeks' desire to avoid German financial control over their economy.

\section{Discussion}

The economic and political situation in the EU at the time of the Greek referendum was critical. This was because the conflict had reached the breaking point, and the idea of countries exiting the union was actively discussed. For instance, the United Kingdom's decision to exit the EU (Brexit) is seen by some as a byproduct of the country's discontentedness with the EU's handling of the financial crisis (Van de Vyver, Leite, Abrams, \& Palmer, 2018). We conducted two studies examined the role of (de)humanization in the economic conflict, particularly from the perspective of the Germans and the Greeks, offering insights into the importance of humanizing the ingroup, along with outgroup dehumanization, in the interpretation of the causes and consequences of the economic conflict and its possible solutions.

Previous work linking dehumanization and conflict (Castano \& Giner-Sorolla, 2006; Čehajić et al., 2009; Leidner et al., 2013) has typically focused only on outgroup dehumanization or ingroup humanization, neglecting the effect of both processes occurring simultaneously and influencing the interpretation of the same economic situation. We addressed these limitations by including both ingroup humanity and outgroup dehumanization. This approach allowed us to compare the different effects of both ingroup humanization and outgroup dehumanization (as suggested by Vaes et al., 2012). Our findings suggest that the picture is complex and that situational context is also very important: Humanity attributions between citizens of each country could have driven and perpetuated the contra- 
dicting opinions about what measures the EU should have taken to solve this situation.

When the Germans believed that they possessed more HU than the Greeks, the effect was marked. This pattern of results predicted viewing Greeks as responsible for the crisis, not properly managing their economy, and not really suffering from the recession. In short, that the Greeks were to blame and things were not that bad. Despite these relationships, the overarching finding was that Germans' beliefs were driven by attitudes, not dehumanization. A possible explanation of the present results could be related to the status asymmetries. Previous researchers found that dehumanization might be triggered by the perception that the other is dehumanizing the ingroup (i.e., meta-dehumanization; Kteily, Hodson, \& Bruneau, 2016). However, it might also be possible that this process does not equally apply to low-versus high-status groups. In the context of our study, Germany was considered one of the wealthiest nations of the EU and thus, a high-status nation. This might have rendered a minimization of the negative outcomes of being dehumanized by a low-status group (i.e., the Greeks). Further studies should address this issue by investigating how high- versus low-status groups react when they are dehumanized.

For the Greeks, the dehumanization was complementary-the Germans were lacking in $\mathrm{HN}$ and thus machine-like, while the ingroup possessed high HN. Moreover, for the Greeks, humanity played a more prominent role in the interpretation of the economic conflict. However, the data seem to indicate that we underestimated the role of Greek $\mathrm{HN}$ as a predictor of a more efficient administration or as a variable that lowers the responsibility attributed to the Greeks (ingroup) for the economic crisis. It seems that for the Greeks, their warmth, flexibility, and cognitive openness (all HN traits), more than their culture or their civic behavior, influenced their understanding of the causes of the crisis and their desire to avoid German control over the Greek economy. Additionally, the ascribed level of HU to the ingroup was, contrary to our predictions, the variable that predicted the perceived suffering during the economic recession.

Complementing these findings, Germans' humanity (i.e., outgroup) seemed to affect the interpretation of the conflict. A possible explanation is that mechanizing the Germans (by the Greeks) might trigger the perception that Germans are actively damaging the Greeks' economy by supporting austerity measures in the EU parliament. This lack of emotionality also seems to trigger the desire to avoid any economic control by the EU, as well as the desire for autonomous decisions. This pattern of results could be understood as an opposition to (dependent) policies that could be perceived as a way to maintain the status quo (Nadler, 2002). Finally, the results also showed an interesting association between the Germans' attribution of $\mathrm{HU}$ traits and the responsibility of the Greeks during the economic recession or support for debt relief. These results seem to indicate that the Greeks assume some ingroup responsibility for the economic recession. However, the Germans' HU was associated with the perception that the Germans were not willing to forgive part of the Greek national debt. This indicates that humanizing others might lead to assuming certain ingroup responsibility for the economic recession. In short, we can conclude that our results indicate that for the Greeks, their own humanity as well as the dehumanization of Germans contributed to shaping the interpretation of the economic conflict.

In general, both processes of mutual outgroup dehumanization and emphasizing ingroup humanity seemed to be associated with the sentiments and interactions between these EU partners locked in conflict. These results show the different effects of ingroup and outgroup humanity, along with attitudes, on the interpretation of the conflict. On the one hand, it seems that ingroup humanity served as a defense mechanism that allowed the group to preserve a positive perception of themselves as not responsible for the crisis, or even as victims. This might serve to mitigate ingroup flaws (Kraus et al., 2017) on the part of the Greeks. On the other hand, results regarding outgroup dehumanization show the opposite pattern. Outgroup dehumanization contributes to highlighting the responsibility of the other and blaming them for the current economic situation. This evidence points out that (de)humanization might trigger the attributional process by placing responsibility on internal and controllable causes (e.g., the Greeks' behavior), while ruling out interpretations based on contextual and uncontrollable factors (e.g., the slowdown of the world economy). This is in line with previous studies about the attributions that people made of disadvantaged groups (Cozzarelli, Wilkinson, \& Tagler, 2001). Future studies should further examine the impact of dehumanization on attributions of poverty.

In short, these exploratory results give us some information about the different functionality of ingroup and outgroup humanity on the interpretation (i.e., attributions) of the same economic issue. Both processes seem to contribute to undermining conflict resolution by following different paths. Therefore, as Vaes et al. (2012) pointed out, both perspectives should be taken into consideration when analyzing an intergroup conflict. Future studies should provide confirmatory evidence of these results by replicating it in a similar national conflict. Moreover, future studies should provide more evidence on the factors that drive the complementary attributions of humanity between groups involved in a conflict. Based on the work of Bain et al. (2009), one can expect cross-cultural differences, with citizens of one country perceiving the ingroup as having one dimension of humanity, while lacking the other. Thus, when comparing these groups with other nations, a complementary attributional process is identified. However, differences in humanity attributions could also be driven by contextual (Delgado, Rodríguez-Pérez, Vaes, Betancor, \& Leyens, 2012) or comparative factors. Specifically, the literature on the compensation effect highlights how groups that are portrayed as higher in one social dimension of perception are also judged as lower in the other dimension (Yzerbyt, Kervyn, \& Judd, 2008). Thus, the complementary attribution of humanity that we found might be motivated by a desire to highlight ingroup strengths and to obscure ingroup flaws. Future studies should disentangle the cultural, comparative, and compensatory reasons behind the complementary attribution of humanity. 
Moreover, these results pointed out some discrepancies regarding the extent to which dehumanization influenced the interpretation of the conflict. Interestingly, humanity predicted the interpretation of the conflict from the perspective of the group experiencing austerity (i.e., Greeks) rather than from the point of view of the group demanding that these measures be enforced (i.e., Germans). We hypothesized that these differences might be driven by the asymmetry reflected in the conflict. It is possible that the Greeks' perceptions about being dehumanized by the Germans was not comparable to the Germans' perceptions about being dehumanized by the Greek population (i.e., meta-dehumanization; Kteily et al., 2016). Future studies might address this issue by analyzing how asymmetries in conflicts shape the attribution of humanity to both the ingroup and the outgroup.

Furthermore, these studies provide insight into dehumanization processes in an ongoing economic conflict. However, it is difficult to determine whether dehumanization fuels the conflict, conflict fuels the dehumanization, or both. Based on previous literature, both possibilities seem likely (Castano \& Giner-Sorolla, 2006; Čehajić et al., 2009; Leidner et al., 2013). Most importantly, this work shows that dehumanization is at play during conflict, not only before and after it. The present pattern of results might vary when comparing conflicts whose origin is several years before, or conflicts that are just arising. Future studies could compare the role of both ingroup and outgroup (de)humanization on different states of conflict, comparing how levels of (de)humanization change during pre/post situations with the level of mutual (de)humanization during the peak of the conflict. Lastly, although the present project would have benefitted from a larger sample size, our aim of studying the conflict during its peak meant that data collection was only undertaken during the week after the referendum.

The present results highlight that economic conflict might be perpetuated by mutual dehumanization. There are several courses of action to address this issue. For instance, promoting a general identity (Albarello \& Rubini, 2012) of Europeans by focusing on shared traits more than on the traits that distinguish one nation from other might shape a more collective identification that could lead to less blame, more aid, and more efficient resolutions of future EU economic crises.

In conclusion, the EU is a union of nations facing shared problems and seeking shared solutions. Unfortunately, the division caused by the economic recession and countries leaving the union seems to be undermining the European project. Europe has changed drastically since the conception of the EU, and the problems inside the EU are not perceived as shared. We suggest that for some people in EU nations, humanity is not an attribute they believe they share. Its seems that dehumanizing other members of the EU contributes to the neglect of the problems inside the EU, whereas humanizing one's own nationality seems to reinforce the perception of the ingroup as not responsible for the problems that may have arisen as a consequence of the economic crisis. Sharing humanity, as well as currencies, favors common causes and common solutions. Perhaps conflict resolution should not only involve acceptance of a common responsibility but also the recognition that citizens from different countries inside the EU are equally human.

\section{Declaration of conflicting interests}

The authors declared no potential conflicts of interest with respect to the research, authorship, and/or publication of this article.

\section{Funding}

The present research was supported by a research scholarship (Programa de movilidad para jóvenes doctorandos CEI-BIOTIC) from the University of Granada and by the Philip Leverhulme Prize (awarded by Steve Loughnan).

\section{References}

Albarello, F., \& Rubini, M. (2012). Reducing dehumanization outcomes towards Blacks: The role of multiple categorization and of human identity. European Journal of Social Psychology, 42(7), 875-882. http://dx.doi.org/10.1002/ejsp.1902

Andrighetto, L., Baldissarri, C., \& Volpato, C. (2017). (Still) modern times: Objectification at work. European Journal of Social Psychology, 47(1), 25-35. http://dx.doi.org/10.1002/ejsp.2190

Bain, P., Park, J., Kwok, C., \& Haslam, N. (2009). Attributing human uniqueness and human nature to cultural groups: Distinct forms of subtle dehumanization. Group Processes E' Intergroup Relations, 12(6), 789-805. http://dx.doi.org/10.1177/1368430209340415

Bandura, A. (1999). Moral disengagement in the perpetration of inhumanities. Personality and Social Psychology Review, 3(3), 193-209. http://dx.doi.org/10.1207/s15327957pspr0303_3

Bar-Tal, D. (1989). Delegitimization: The extreme case of stereotyping. In D. Bar-Tal, C. F. Grauman, A. Kruglanski, \& W. Stroebe (Eds.), Stereotyping and prejudice: Changing conceptions (pp. 169-182). New York: Springer.

Bastian, B., Jetten, J., \& Radke, H. R. M. (2012). Cyber-dehumanization: Violent video game play diminishes our humanity. Journal of Experimental Social Psychology, 48(2), 486-491. http://dx.doi.org/10.1016/j.jesp.2011.10.009

Bastian, B., Laham, S. M., Wilson, S., Haslam, N., \& Koval, P. (2011). Blaming, praising, and protecting our humanity: The implications of everyday dehumanization for judgments of moral status. The British Journal of Social Psychology, 50(3), 469-483. http://dx.doi.org/10.1348/014466610X521383

BBC News. (2010). Europe's PIGS: Country by country February 11, Retrieved from:. http://news.bbc.co.uk/2/hi/8510603.stm

Capozza, D., Andrighetto, L., Di Bernardo, G. A., \& Falvo, R. (2011). Does status affect intergroup perceptions of humanity? Group Processes \& Intergroup Relations, 15(3), 363-377. http://dx.doi.org/10.1177/1368430211426733

Castano, E., \& Giner-Sorolla, R. (2006). Not quite human: Infrahumanization in response to collective responsibility for intergroup killing. Journal of Personality and Social Psychology, 90(5), 804-818. http://dx.doi.org/10.1037/0022-3514.90.5.804

Čehajić, S., Brown, R., \& Gonzalez, R. (2009). What do I care? Perceived ingroup responsibility and dehumanization as predictors of empathy felt for the victim group. Group Processes E' Intergroup Relations, 12(6), 715-729. http://dx.doi.org/10.1177/1368430209347727

Cozzarelli, C., Wilkinson, A. V., \& Tagler, M. J. (2001). Attitudes toward the poor and attributions for poverty. Journal of Social Issues, 57, 207-227. http://dx.doi.org/10.1111/0022-4537.00209

Delgado, N., Rodríguez-Pérez, A., Vaes, J., Betancor, V., \& Leyens, J. P. h. (2012). Contextual variations of infra-humanization: The role of physical context and territoriality. Basic and Applied Social Psychology, 34, 456-466. http://dx.doi.org/10.1080/01973533.2012.712020

Faul, F., Erdfelder, E., Buchner, A., \& Lang, A. G. (2009). Statistical power analyses using $G^{*}$ Power 3.1: Tests for correlation and regression analyses. Behavior Research Methods, 41(4), 1149-1160. http://dx.doi.org/10.3758/BRM.41.4.1149

Haslam, N. (2006). Dehumanization: An integrative review. Personality and Social Psychology Review, 10(3), 252-254. http://dx.doi.org/10.1207/s15327957pspr1003_4 
Haslam, N., \& Loughnan, S. (2014). Dehumanization and infrahumanization. Annual Review of Psychology, 65(1), 399-423. http://dx.doi.org/10.1146/annurev-psych-010213-115045

Henry, P. J., Reyna, C., \& Weiner, B. (2004). Hate welfare but help the poor: How the attributional content of stereotypes explains the paradox of reactions to the destitute in America. Journal of Applied Social Psychology, 34, 34-58. http://dx.doi.org/10.1111/j.1559-1816.2004.tb02536.x

Iatridis, T. (2013). Occupational status differences in attributions of uniquely human emotions. British Journal of Social Psychology, 52 431-449. http://dx.doi.org/10.1111/j.2044-8309.2011.02094.x

Koval, P., Laham, S. M., Haslam, N., Bastian, B., \& Whelan, J. A. (2011) Our flaws are more human than yours: Ingroup bias in humanizing negative characteristics. Personality E Social Psychology Bulletin, 38(3), 283-295. http://dx.doi.org/10.1177/0146167211423777

Kraus, M. W., Park, J. W., \& Tan, J. (2017). Signs of social class: The experience of economic inequality in everyday life. Perspectives on Psychological Science, 12(3), 422-435. http://dx.doi.org/10.1177/1745691616673192

Kteily, N., Hodson, G., \& Bruneau, E. (2016). They see us as less than human: Meta-dehumanization predicts intergroup conflict via reciprocal dehumanization. Journal of Personality and Social Psychology, 110(3), 343-370. http://dx.doi.org/10.1037/pspa0000044

Leidner, B., Castano, E., \& Ginges, J. (2013). Dehumanization, retributive and restorative justice, and aggressive versus diplomatic intergroup conflict resolution strategies. Personality E Social Psychology Bulletin, 39(2), 181-192. http://dx.doi.org/10.1177/0146167212472208

Leidner, B., Castano, E., Zaiser, E., \& Giner-Sorolla, R. (2010). Ingroup glorification, moral disengagement, and justice in the context of collective violence. Personality and Social Psychology Bulletin, 36(8), 1115-1129. http://dx.doi.org/10.1177/0146167210376391

Loughnan, S., Haslam, N., Sutton, R. M., \& Spencer, B. (2014). Dehumanization and social class: Animality in the stereotypes of "White trash," “Chavs," and "Bogans". Social Psychology, 45(1), 54-61. http://dx.doi.org/10.1027/1864-9335/a000159

Loughnan, S., Pina, A., Vasquez, E. A., \& Puvia, E. (2013). Sexual objectification increases rape victim blame and decreases perceived suffering. Psychology of Women Quarterly, 37(4), 455-461. http://dx.doi.org/10.1177/0361684313485718

Martínez, R., Rodríguez-Bailón, R., \& Moya, M. (2012). Are they animals or machines? Measuring dehumanization. The Spanish Journal of Psychology, 15(3), 1110-1122. http://dx.doi.org/10.5209/rev_SJOP.2012.v15.n3.39401
Nadler, A. (2002). Inter-group helping relations as power relations: Maintaining or challenging social dominance between groups through helping. Journal of Social Issues, 58, 487-502. http://dx.doi.org/10.1111/1540-4560.00272

New Statesman. (2012). Europe's most dangerous leader June 25, Retrieved from. http://www.newstatesman.com/blogs/staggers/2012/06/newstatesman-cover-25-june

Paladino, M. P., \& Vaes, J. (2009). Ours is human: On the pervasiveness of infra-humanization in intergroup relations. British Journal of Social Psychology, 48, 237-251. http://dx.doi.org/10.1348/014466608X322882

Sainz, M., Martínez, R., Moya, M., \& Rodríguez-Bailón, R. (2018). Animalizing the disadvantaged, mechanizing the wealthy: The convergence of socioeconomic status and humanity attributions. International Journal of Psychology, http://dx.doi.org/10.1002/ijop.12485

Vaes, J., \& Muratore, M. (2013). Defensive dehumanization in the medical practice: A cross-sectional study from a health care worker's perspective. British Journal of Social Psychology, 52(1), 180-190. http://dx.doi.org/10.1111/bjso.1200

Vaes, J., Leyens, J.-P., Paladino, M. P., \& Miranda, M. P. (2012). We are human, they are not: Driving forces behind outgroup dehumanisation and the humanisation of the ingroup. European Review of Social Psychology, 23(1), 64-106. http://dx.doi.org/10.1080/10463283.2012.665

Van de Vyver, J., Leite, A., Abrams, D., \& Palmer, S. (2018). Brexit or Bremain? A person and social analysis of voting decisions in the EU referendum. Journal of Community $\mathcal{E}$ Applied Social Psychology, 28, 65-79. http://dx.doi.org/10.1002/casp.2341

Yzerbyt, V. Y., Kervyn, N., \& Judd, C. M. (2008). Compensation versus halo: The unique relations between the fundamental dimensions of social judgment. Personality and Social Psychology Bulletin, 34, 1110-1123. http://dx.doi.org/10.1177/0146167208318602

BILD Zeitung. (2015). No! No more billions for the greedy Greeks.. February 26, Retrieved from http://www.bild.de/politik/inland/griechenland-krise/keine-weiteren -milliarden-fuer-die-gierigen-griechen-39925224.bild.html 